\title{
A Global and Unified Trait Database for Aquatic Macroinvertebrates: The Missing Piece in a Global Approach
}

\author{
Alain Maasri ${ }^{1,2 *}$ \\ ${ }^{1}$ The Academy of Natural Sciences of Drexel University, Philadelphia, PA, United States, ${ }^{2}$ Department of Ecosystem \\ Research, Leibniz-Institute of Freshwater Ecology and Inland Fisheries (IGB), Berlin, Germany
}

Keywords: macroinvertebrates, traits, functional ecology, aquatic ecosystems, Nearctic fauna, Palearctic fauna

\section{OPEN ACCESS}

Edited by:

Sergi Sabater

University of Girona, Spain

Reviewed by:

loannis Karaouzas,

Hellenic Centre for Marine Research

(HCMR), Greece

*Correspondence:

Alain Maasr

alainmaasri@gmail.com

Specialty section:

This article was submitted to

Freshwater Science,

a section of the journal

Frontiers in Environmental Science

Received: 01 March 2019

Accepted: 25 April 2019

Published: 10 May 2019

Citation:

Maasri A (2019) A Global and Unified

Trait Database for Aquatic

Macroinvertebrates: The Missing

Piece in a Global Approach.

Front. Environ. Sci. 7:65.

doi: 10.3389/fenvs.2019.00065
Traits of an organism define its relationship to local biotic and abiotic environmental factors. They offer an understanding of mechanistic and selective processes that link species to their environment. Traits have been presented as an alternative way to explore biodiversity and to predict changes in communities across environmental gradients. This led to increasing research on trait-based ecology and trait analyses have undoubtedly proven efficiency in both basic and applied aquatic ecology. Thus, much interest in how traits are to be analyzed has been given. Among those the development of a taxa-specific combination of variables described as a taxon's functional trait niche (see, Poff et al., 2006), and the development of multiple functional-diversity analytic methodologies (see review, Schmera et al., 2017).

Using traits instead of species diversity initially limits probabilities on which many analytic tools are based. The number of species to be found in a certain biotope surpasses often the number of traits expressed by these species, the later being predefined by scientists. However, the use of a predefined and often variable number of descriptive traits and trait modalities is widely accepted in the scientific community and has undoubtedly a direct impact on many research outcomes. When converting a theoretically larger number of taxa to a reduced number of traits, the method used to determine and describe these traits in different modalities gain automatically paramount importance. For instance, when considering the North American trait database (Poff et al., 2006; Vieira et al., 2006), 20 traits for lotic macroinvertebrates described in 54 modalities are available. The European database (Charvet et al., 2000; Usseglio Polatera et al., 2000) displays 22 traits ( 20 when removing geographically bound traits, and traits of macroinvertebrates from non-lotic habitats) described in 119 modalities (108 when describing 20 traits). Most often similar traits, destined to describe a similar biological or ecological feature of an organism, are not described in a similar way across these two databases. The number of modalities used to describe each trait can vary substantially (Figure 1). For example, when considering the dispersal of aquatic macroinvertebrates, the European database categorizes dispersal in four modalities: active-aquatic, active-aerial, passive-aquatic, passive-aerial. The corresponding trait in the North American database displays a distinct set of modalities that are not completely comparable with their European equivalents. These can include, low and high female dispersal; weak and strong adult flight, and occurrence in drift categorized as rare, common, and strong. This is one of many examples that illustrate the divergence between the two most extensively used trait databases describing the Palearctic and Nearctic aquatic macroinvertebrate fauna.

The proposed unified terminology by Schmera et al. (2015) constitutes certainly a milestone in the advancement toward an appropriate and unified algebraically correct treatment of traits in aquatic ecology. The unified terminology and more importantly the transformation of ordinal and nominal data scales into a nominal scale with two states (yes or no) will facilitate the interpretation results across scientific studies. However, this alone will not solve the distortion developed in multiple functional-diversity indices when using the North American trait database 


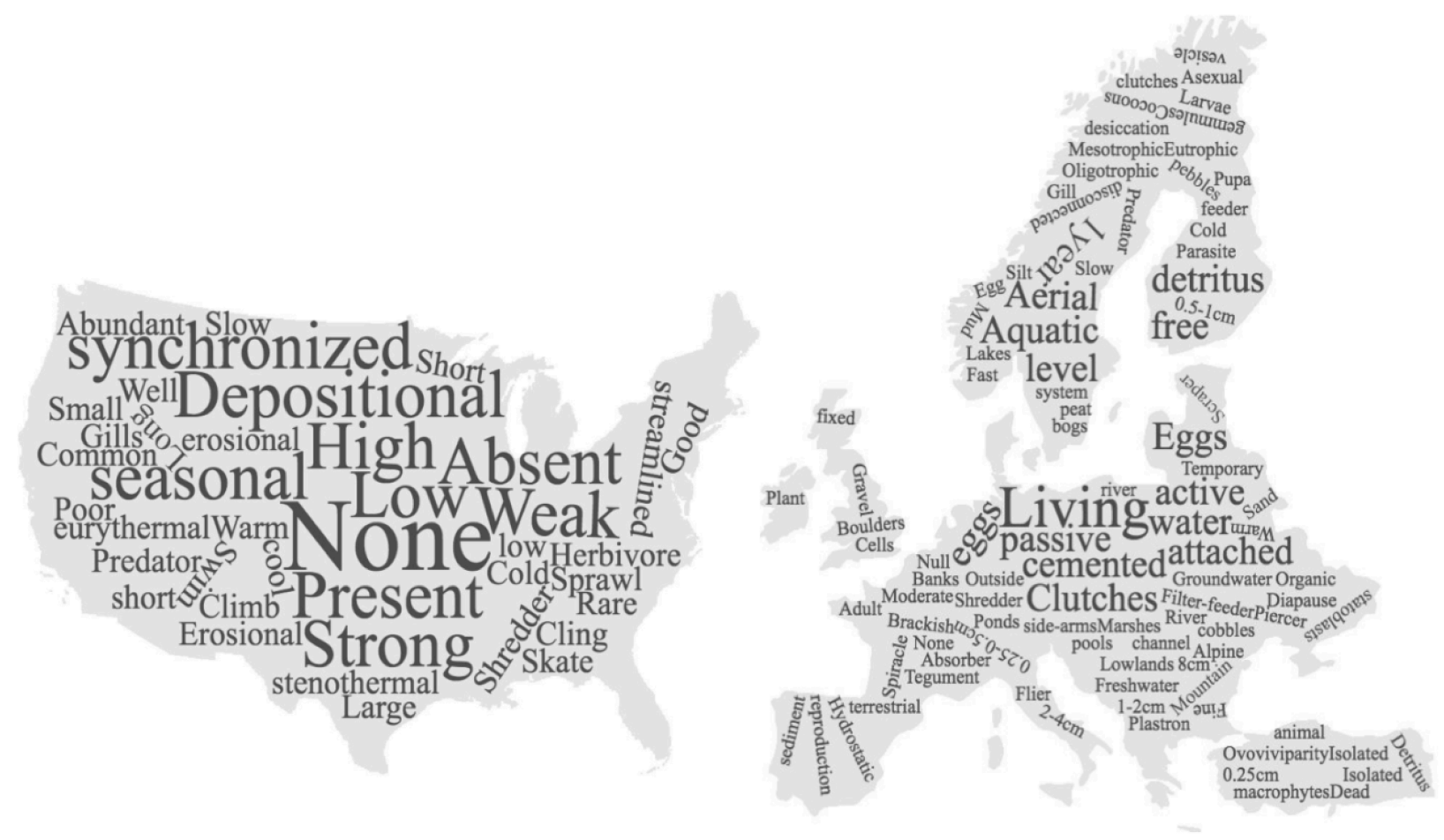

FIGURE 1 | Diagram displaying the different trait modalities used in the North American and the European trait databases for aquatic macroinvertebrates.

vs. the European trait database. A similar assemblage of macroinvertebrates described by both of these databases will produce different functional-diversity indices (Mason et al., 2005).

Both classifications have certainly the merit to exist and provide valuable descriptive information on of relationships between aquatic macroinvertebrates and their environment. However, the use of similar analytic tools (see above) on functional assemblages described by a different set of traits and modalities hampers the development of a sound comparative literature assessment and can be misleading in certain study cases.

How many traits and how many trait modalities are needed to adequately describe the relationship of an organism to its environment remains an open question. However, in light of the exponential advancement of trait-based research, answering this question, and rooting for the implementation of a unified global trait database where traits are described by a coherent set of modalities will have significant long-term positive effects. This will constitute the foundation for a reliable global approach to trait-based research in aquatic ecology and will certainly enhance the scientific accuracy and comparability of many scientific studies examining aquatic communities. Characteristics of a unified trait database will need to be defined, but those should lead to (1) increasing the resolution of available information, and (2) optimizing available analytic tools. Such substantial effort will be key to enhancing stream macrosystem ecology research, as ecosystem processes and properties are increasingly examined at a global scale.

\section{AUTHOR CONTRIBUTIONS}

This manuscript was written by AM and is based on his perception of challenges in a global approach of trait-based ecology in stream ecosystems.

\section{FUNDING}

Financial support for the author was provided by the Macrosystem Biology Program of the U.S. National Science Foundation (NSF, grant no. 1442595), and additional funding was provided by the German Federal Ministry of Education and Research (BMBF, grant no. 01LN1320A).

\section{ACKNOWLEDGMENTS}

The author is grateful for stimulating scientific discussions with Dr. James H. Thorp and Dr. Sonja C. Jähnig, in addition to enthusiastic conversations with members of the Macroecological Riverine Synthesis project (MACRO, http://www.macrorivers. $\operatorname{org} /)$. 


\section{REFERENCES}

Charvet, S., Statzner, B., Usseglio Polatera, P., and Dumont, B. (2000). Traits of benthic macroinvertebrates in semi-natural French stream: an initial application to biomonitoring in Europe. Freshwater Biol. 43, 277-296. doi: 10.1046/j.1365-2427.2000. 00545.x

Mason, N. W. H., Mouillot, D., Lee, W. G., and Wilson, J. B. (2005). Functional richness, functional evenness and functional divergence: the primary components of functional diversity. Oikos 111, 112-118. doi: 10.1111/j.0030-1299.2005. 13886.x

Poff, N. L., Olden, J. D., Vieira, N. K. M., Finn, D. S., Simmons, M. P., and Kondratieff, B. C. (2006). Functional trait niches of North American lotic insects: traits-based ecological applications in light of phylogenetic relationships. J. North Am. Benthol. Soc. 25, 730-755. doi: 10.1899/08873593(2006)025[0730:FTNONA]2.0.CO;2

Schmera, D., Heino, J., Podani, J., Erös, T., and Dolédec, S. (2017). Functional diversity: a review of methodology and current knowledge in freshwater macroinvertebrate research. Hydrobiologia 787, 27-44. doi: 10.1007/s10750-0162974-5
Schmera, D., Podani, J., Heino, J., Erõs, T., and Poff, N. L. (2015). A proposed unified terminology of species traits in stream ecology. Freshwater Sci. 34, 823-830. doi: 10.1086/681623

Usseglio Polatera, P., Bournaud, M., Richoux, P., and Tachet, H. (2000). Biological and ecological traits of benthic freshwater macroinvertebrates: relationships and definition of groups with similar traits. Freshwater Biol. 43, 175-205. doi: 10.1046/j.1365-2427.2000.00535.x

Vieira, N. K. M., Poff, N. L., Carlisle, D. M., Moulton, S. R., Koski, M. L., and Kondratieff, C. (2006). A Database of Lotic Invertebrate Traits for North America. US Geological Survey Data Series. Available online at: http://pubs. water.usgs.gov/ds187

Conflict of Interest Statement: The author declares that the research was conducted in the absence of any commercial or financial relationships that could be construed as a potential conflict of interest.

Copyright (C) 2019 Maasri. This is an open-access article distributed under the terms of the Creative Commons Attribution License (CC BY). The use, distribution or reproduction in other forums is permitted, provided the original author(s) and the copyright owner(s) are credited and that the original publication in this journal is cited, in accordance with accepted academic practice. No use, distribution or reproduction is permitted which does not comply with these terms. 